\title{
Behavioral and Clinical Characteristics of American Indian/Alaska Native Adults in HIV Care — Medical Monitoring Project, United States, 2011-2015
}

\author{
Amy R. Baugher, $\mathrm{MPH}^{1}$; Linda Beer, $\mathrm{PhD}^{1}$; Heather M. Bradley, $\mathrm{PhD}^{1}$; Mary E. Evans, $\mathrm{MD}^{2}$; Qingwei Luo, $\mathrm{MS}^{3}$; R. Luke Shouse, $\mathrm{MD}^{1}$
}

The rate of diagnosis of human immunodeficiency virus (HIV) infection among American Indians and Alaska Natives (AI/ANs) in 2016 (10.2 per 100,000 population) was the fourth highest among seven racial/ethnic groups in the United States (1); the number of diagnoses of HIV infection among AI/AN persons increased by 70\%, from 143 in 2011 to 243 in 2016 (1). However, little has been published about the sociodemographic, behavioral, and clinical characteristics of AI/AN patients with HIV infection in care because small sample sizes have led to infrequent analysis of AI/AN-specific estimates (2) and because of underestimation of AI/AN race/ ethnicity in surveillance and other data sources (3). CDC analyzed data from the Medical Monitoring Project (MMP), a surveillance system that collects information about the experiences and needs of persons with diagnosed HIV infection, collected during 2011-2015 among AI/AN adults receiving HIV medical care. The results indicated that $64 \%$ of AI/AN patients with HIV infection in care achieved sustained viral suppression, and $76 \%$ achieved viral suppression at their most recent viral load test within the past 12 months, which is below the national HIV prevention goal of $80 \%$, but comparable to or better than some other racial/ethnic groups (4). Based on self-report, $51 \%$ of AI/AN patients with HIV infection had incomes at or below the U.S. Department of Health and Human Services' (HHS) annual poverty limit, 27\% had symptoms of depression, $78 \%$ reported internalized HIV-related stigma, and $20 \%$ reported binge drinking in the past 30 days. To improve the health of AI/AN patients with HIV infection, it is important that health care providers, tribal organizations, and state and local health departments consider the sociodemographic and behavioral barriers to AI/AN patients with HIV infection achieving viral suppression and design care plans that seek to eliminate those barriers.
MMP used a three-stage sample design (states and territories, facilities, patients). Response rates were 100\% (states and territories), $83 \%-85 \%$ (range across cycles for facilities), and $49 \%-55 \%$ (patients). Data were collected using face-to-face or telephone interviews and medical record abstraction during June 2011-May 2015. Data were weighted for unequal selection probabilities and nonresponse (5). Weighted prevalence estimates describing the sociodemographic, behavioral, and clinical characteristics of AI/AN patients with HIV infection in care were calculated with accompanying $95 \%$ confidence intervals (CIs). Based on mental health results found in this descriptive analysis, mental health and peer group support services received and needed were also described.

\section{INSIDE}

$$
\begin{aligned}
& 1410 \text { Human Rabies — Virginia, } 2017 \\
& 1415 \text { Wound Botulism Outbreak Among Persons Who }
\end{aligned}
$$

Continuing Education examination available at https://www.cdc.gov/mmwr/cme/conted_info.html\#weekly.

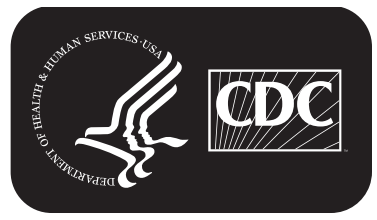

U.S. Department of Health and Human Services Centers for Disease Control and Prevention 
AI/AN classification was determined by self-identified AI/ AN race, regardless of ethnicity or other racial group identity (2). Poverty was defined as income at or below the HHS annual poverty guidelines.* Depression was defined as selfreported symptoms consistent with a diagnosis of major/other depression in the past 2 weeks based on the Patient Health Questionnaire-8 (PHQ-8) scale with major/other depression defined as a PHQ-8 score $\geq 2$. Binge drinking was defined as consumption of four or more (females) or five or more (males) alcoholic drinks in one sitting in the past 30 days. Antiretroviral therapy (ART) adherence was defined as taking all prescribed HIV medicines in the past 3 days. Sustained viral suppression was defined as $<200$ copies of viral $\mathrm{RNA} / \mathrm{mL}$ in all viral load tests during the past 12 months. Need for support services was defined as needing, but not receiving, mental health or HIV peer group support services during the past 12 months. AI/AN patients (666) accounted for 3.6\% $(95 \% \mathrm{CI}=3.1-4.1)$ of the MMP population. Among AI/AN patients with HIV infection, $65 \%$ identified as being part of more than one racial group, and 29\% identified as Hispanic/Latino ethnicity (Table 1). Fifty-one percent had household incomes at or below the HHS poverty guidelines, $12 \%$ experienced homelessness in the past 12 months, and $6 \%$ had been incarcerated in the past

\footnotetext{
* Poverty guidelines as defined by the U.S. Department of Health and Human Services. https://aspe.hhs.gov/poverty/faq.cfm.
}

12 months. Internalized HIV-related stigma ${ }^{\dagger}$ was reported by $78 \%$ of patients, and $37 \%$ experienced health care discrimination since testing positive for HIV. ${ }^{\S}$

Among AI/AN patients with HIV infection in care, $27 \%$ had symptoms consistent with major/other depression in the past 2 weeks, $12 \%$ were dissatisfied with their social support, $20 \%$ reported binge drinking, 32\% used noninjection drugs in the past 12 months, $5 \%$ injected drugs in the past 12 months, and $46 \%$ currently smoked cigarettes (Table 2). Eight percent of AI/AN patients with HIV infection had condomless sex with a partner who had a negative or unknown HIV status while the patient was not sustainably virally suppressed during the past 12 months. In terms of clinical characteristics, $86 \%$ of AI/AN patients on ART were adherent, $64 \%$ had achieved sustained viral suppression, and $76 \%$ had achieved viral suppression as of their most recent viral load test in the past 12 months.

Peer support group services were received by $17 \%$ of AI/ AN patients, whereas $11 \%$ needed but did not receive these

\footnotetext{
$\dagger$ Any internalized HIV-related stigma was defined as agreeing with any of the following statements from the Internalized AIDS-Related Stigma Scale: it is difficult to tell people about my HIV infection, being HIV-positive makes me feel dirty, I feel guilty that I am HIV-positive, I am ashamed that I am HIV-positive, I sometimes feel worthless because I am HIV-positive, and I hide my HIV status from others.

${ }^{\S}$ Health care discrimination was defined as a health care worker exhibiting hostility or lack of respect, giving the patient less attention than other patients, or refusing the patient service since the patient tested positive for HIV.
}

The MMWR series of publications is published by the Center for Surveillance, Epidemiology, and Laboratory Services, Centers for Disease Control and Prevention (CDC), U.S. Department of Health and Human Services, Atlanta, GA 30329-4027.

Suggested citation: [Author names; first three, then et al., if more than six.] [Report title]. MMWR Morb Mortal Wkly Rep 2018;67:[inclusive page numbers]

\section{Centers for Disease Control and Prevention Robert R. Redfield, MD, Director \\ Anne Schuchat, MD, Principal Deputy Director \\ Leslie Dauphin, PhD, Acting Associate Director for Science \\ Barbara Ellis, PhD, MS, Acting Director, Office of Science Quality \\ Chesley L. Richards, MD, MPH, Deputy Director for Public Health Scientific Services}

William R. Mac Kenzie, MD, Acting Director, Center for Surveillance, Epidemiology, and Laboratory Services

MMWR Editorial and Production Staff (Weekly)

Charlotte K. Kent, PhD, MPH, Acting Editor in Chief, Executive Editor

Jacqueline Gindler, MD, Editor

Mary Dott, MD, MPH, Online Editor

Teresa F. Rutledge, Managing Editor

Douglas W. Weatherwax, Lead Technical Writer-Editor

Glenn Damon, Soumya Dunworth, PhD, Teresa M. Hood, MS, Technical Writer-Editors

Matthew L. Boulton, MD, MPH Virginia A. Caine, MD

Katherine Lyon Daniel, PhD

Jonathan E. Fielding, MD, MPH, MBA

David W. Fleming, MD

William E. Halperin, MD, DrPH, MPH
MMWR Editorial Board Timothy F. Jones, MD, Chairman Robin Ikeda, MD, MPH Phyllis Meadows, PhD, MSN, RN Jewel Mullen, MD, MPH, MPA Jeff Niederdeppe, PhD Patricia Quinlisk, MD, MPH
Martha F. Boyd, Lead Visual Information Specialist Maureen A. Leahy, Julia C. Martinroe, Stephen R. Spriggs, Tong Yang, Visual Information Specialists

Quang M. Doan, MBA, Phyllis H. King, Terraye M. Starr, Moua Yang, Information Technology Specialists
Stephen C. Redd, MD

Patrick L. Remington, MD, MPH

Carlos Roig, MS, MA

William Schaffner, MD

Morgan Bobb Swanson, BS 
TABLE 1. Sociodemographic characteristics of American Indian/ Alaska Native (AI/AN)* adults living with human immunodeficiency virus (HIV) infection receiving medical care $(\mathrm{N}=666)$ - Medical Monitoring Project, United States, 2011-2015

\begin{tabular}{|c|c|c|}
\hline Characteristic & Total & $\%^{\dagger}\left(95 \% \mathrm{Cl}^{\S}\right)$ \\
\hline \multicolumn{3}{|l|}{ Race } \\
\hline Single-race AI/AN & 249 & $36(31-40)$ \\
\hline Multiple-race AI/AN & 417 & $65(60-69)$ \\
\hline \multicolumn{3}{|l|}{ Ethnicity } \\
\hline Al/AN, non-Hispanic/Latino & 455 & $71(65-77)$ \\
\hline Al/AN, Hispanic/Latino & 211 & $29(23-35)$ \\
\hline \multicolumn{3}{|l|}{ Gender } \\
\hline Male & 491 & $74(69-78)$ \\
\hline Female & 157 & $23(20-27)$ \\
\hline Transgender" & 18 & $3(2-5)$ \\
\hline \multicolumn{3}{|l|}{ Age group (yrs) } \\
\hline $18-29$ & 45 & $7(5-9)$ \\
\hline $30-39$ & 106 & $16(14-19)$ \\
\hline $40-49$ & 230 & $34(30-37)$ \\
\hline$\geq 50$ & 285 & $43(40-47)$ \\
\hline \multicolumn{3}{|l|}{ Sexual identity } \\
\hline Homosexual & 279 & $43(39-48)$ \\
\hline Heterosexual & 306 & $46(41-52)$ \\
\hline Bisexual & 67 & $10(8-13)$ \\
\hline \multicolumn{3}{|l|}{ Education } \\
\hline$<$ High school & 172 & $25(22-29)$ \\
\hline $\begin{array}{l}\text { High school/General educational } \\
\text { development certificate }\end{array}$ & 163 & $23(20-26)$ \\
\hline$>$ High school & 331 & $51(47-56)$ \\
\hline \multicolumn{3}{|c|}{ Household income at/below poverty in past 12 months ${ }^{* *}$} \\
\hline Yes & 334 & $51(46-55)$ \\
\hline No & 308 & $50(45-54)$ \\
\hline \multicolumn{3}{|l|}{ Homeless in past 12 months ${ }^{\dagger \dagger}$} \\
\hline Yes & 78 & $12(9-14)$ \\
\hline No & 588 & $88(86-91)$ \\
\hline \multicolumn{3}{|l|}{ Jail in past 12 months } \\
\hline Yes & 40 & $6(4-8)$ \\
\hline No & 626 & $94(92-96)$ \\
\hline \multicolumn{3}{|l|}{ Health insurance in past 12 months } \\
\hline Private only & 141 & $22(19-26)$ \\
\hline Any public & 445 & $65(61-70)$ \\
\hline Only Ryan White coverage or uninsured & 76 & $12(9-16)$ \\
\hline \multicolumn{3}{|l|}{ Any HIV-related stigma§§ } \\
\hline Yes & 519 & $78(74-81)$ \\
\hline No & 140 & $22(19-26)$ \\
\hline \multicolumn{3}{|l|}{ Any health care discrimination ๆๆ } \\
\hline Yes & 241 & $37(32-42)$ \\
\hline No & 417 & $63(58-68)$ \\
\hline
\end{tabular}

Abbreviation: $\mathrm{Cl}$ = confidence interval.

* Self-identified Al/AN race, regardless of ethnicity or other racial groups.

† Percentages are weighted percentages and might not sum to $100 \%$ because of rounding.

$\S 95 \%$ Cls incorporate weighted percentages

I Patients were classified as transgender if sex at birth and gender reported by patient were different, or if patient's gender identity was transgender.

** Poverty guidelines as defined by the U.S. Department of Health and Human Services. https://aspe.hhs.gov/poverty/faq.cfm.

${ }^{+\dagger}$ Living on the street, in a shelter, in a single-room-occupancy hotel, or in a car.

$\S \S$ Agreed with any of the following statements: it is difficult to tell people about my HIV infection, being HIV-positive makes me feel dirty, I feel guilty that I am HIV positive, I am ashamed that I am HIV-positive, I sometimes feel worthless because I am HIV-positive, and I hide my HIV status from others.

กๆ Health care discrimination was defined as a health care worker exhibiting hostility or lack of respect, giving the patient less attention than others, or refusing the patient service since the patient tested positive for HIV.
TABLE 2. Behavioral and clinical characteristics of American Indian/ Alaska Native (AI/AN)* adults living with human immunodeficiency virus (HIV) infection receiving medical care $(\mathrm{N}=666)$ - Medical Monitoring Project, United States, 2011-2015

\begin{tabular}{lrr}
\hline Characteristic & Total & $\%^{\dagger}\left(95 \% \mathrm{Cl}^{\S}\right)$ \\
\hline $\begin{array}{l}\text { Depression in past 2 weeks } \\
\text { Major/Other depression }\end{array}$ & 169 & $27(23-30)$ \\
None & 484 & $73(70-77)$ \\
Satisfied with social support & & \\
Very dissatisfied & 42 & $6(5-8)$ \\
Somewhat dissatisfied & 39 & $6(4-8)$ \\
Somewhat satisfied & 141 & $24(20-28)$ \\
Very satisfied & 382 & $64(60-67)$ \\
Binge drinking in past 30 days & & \\
Yes & 132 & $20(17-23)$ \\
No & 524 & $80(77-83)$ \\
Any noninjection drugs in past 12 months & & \\
Yes & 216 & $32(27-35)$ \\
No & 445 & $68(64-73)$ \\
Injected drugs in past 12 months & & \\
Yes & 35 & $5(3-7)$ \\
No & 625 & $95(93-97)$ \\
Currently smokes cigarettes & & \\
Yes & 302 & $46(42-50)$ \\
No & 359 & $55(50-58)$
\end{tabular}

Sex without a condom with partner with HIV-negative or unknown status in past 12 months

$\begin{array}{lrr}\text { Yes } & 87 & 14(11-17) \\ \text { No } & 540 & 86(83-89)\end{array}$

Sex without a condom with HIV-negative or unknown status partners while not sustainably virally suppressed in past 12 months

$\begin{array}{lrr}\text { Yes } & 49 & 8(5-10) \\ \text { No } & 578 & 92(90-95) \\ \text { ART adherence** } & & \\ \text { 100\% adherent } & 519 & 86(83-90) \\ \text { Not 100\% adherent } & 87 & 14(11-17) \\ \text { Sustained viral suppression in past 12 months } & & \\ \text { Yes } & 432 & 64(60-68) \\ \text { No } & 234 & 36(32-41) \\ \text { Most recent viral load suppressed in past 12 months } & \\ \text { Yes } & 512 & 76(73-80) \\ \text { No } & 154 & 24(20-27)\end{array}$

Abbreviations: $\mathrm{ART}=$ antiretroviral therapy; $\mathrm{Cl}=$ confidence interval.

* Self-identified AI/AN race, regardless of ethnicity or other racial groups.

${ }^{\dagger}$ Percentages are weighted percentages and might not sum to $100 \%$ because of rounding.

$\S 95 \% \mathrm{Cls}$ incorporate weighted percentages.

" Consumption of four or more (females) or five or more (males) alcoholic drinks in one sitting in the past 30 days.

**Taking all prescribed HIV medicines in the past 3 days.

services (Figure). Approximately one third of AI/AN patients received mental health services, and $8 \%$ needed but did not receive mental health services.

\section{Discussion}

In this analysis, levels of viral suppression among AI/AN patients with HIV infection in care were suboptimal. Moreover, compared with other racial/ethnic groups, AI/AN patients have a higher rate of poverty, which is associated with poor physical and mental health outcomes (1). The prevalence of 
FIGURE. Mental health and peer group support service needs* among American Indian/Alaska Native $(\mathrm{Al} / \mathrm{AN})^{\dagger}$ adults receiving human immunodeficiency virus (HIV) care $(\mathrm{N}=666)$ - Medical Monitoring Project, United States, 2011-2015

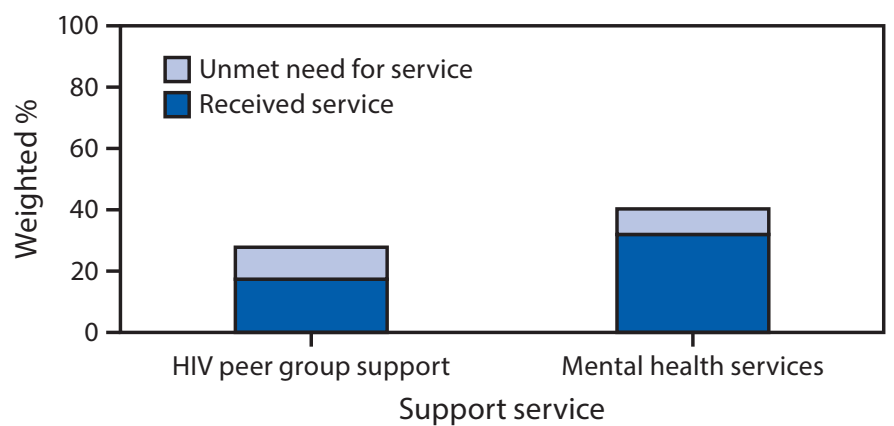

* Need was defined as needing, but not receiving mental health or HIV peer group support services during the past 12 months.

† Self-identified Al/AN race, regardless of ethnicity or other racial groups.

major/other depression (27\%) among AI/AN patients in HIV care was similar to that among all adult patients in HIV care (25\%) (6). The prevalence of stigma (78\%) among AI/AN patients in HIV care, although high, was also similar to stigma among all adult patients in HIV care (79\%) (7). The high prevalence of poverty, depression, stigma, and alcohol use in this population might be caused in part by racial and historical inequities and is not intrinsic to AI/AN cultures (2). Receiving culturally appropriate mental health and peer group support services could reduce symptoms of depression and increase social support (8); in this analysis, some AI/AN patients with HIV infection needed but did not receive these services.

Despite factors such as poverty and depression, which are often associated with suboptimal achievement of viral suppression, the prevalence of viral suppression among AI/AN patients in HIV care was similar to or higher than that among other racial/ethnic groups. AI/AN patients had prevalences of sustained viral suppression that were similar to those among white patients $(66 \%)$ and higher than those among black (49\%) and Hispanic/Latino (59\%) patients in HIV care (9). However, the prevalence of viral suppression among AI/AN patients was lower than the national prevention goal of $80 \%$ for persons with diagnosed HIV infection.

The findings in this report are subject to at least three limitations. First, analysts pooled multiple years of data and could not analyze trends over time because of the small sample size of AI/AN patients in each MMP cycle year. Second, although the MMP sampling design was intended to represent all adult patients with HIV infection in outpatient settings in the United States, it did not include Indian Health Services (IHS) facilities, tribal lands, or some areas with a high concentration of AI/ AN persons; however, the majority of AI/AN persons do not

\section{Summary \\ What is already known about this topic?}

In 2016, American Indians/Alaska Natives (Al/ANs) had the fourth highest human immunodeficiency virus (HIV) infection diagnosis rate among all racial/ethnic groups. During $2011-$ 2016, diagnoses of HIV infection among AI/AN patients increased by $70 \%$. Little has been published about characteristics of $\mathrm{Al} / \mathrm{AN}$ patients with HIV infection.

What is added by this report?

Among adults receiving HIV care from 2011 to 2015, Al/AN patients had high poverty levels (51\%), depression (27\%), HIV stigma (78\%), and suboptimal sustained HIV viral suppression (64\%).

What are the implications for public health practice?

Providers serving Al/AN patients should offer screening and referrals for mental health and peer support services to improve the health of this population and help them achieve viral suppression.

live on tribal lands (10). Finally, interview data were obtained by self-report, which might be susceptible to recall or social desirability biases.

From 2011 to 2016, diagnoses of HIV infection among AI/ AN patients increased by 70\% (1). CDC is currently working with IHS and tribal leaders to implement effective, scalable prevention approaches to support $\mathrm{AI} / \mathrm{AN}$ patients. In light of the fact that almost $80 \%$ of AI/AN patients with HIV infection reported experiencing stigma related to their HIV status, and that more than a third reported experiencing discrimination in health care settings, it is evident that culturally appropriate HIV education, interventions, and care remain priorities (2). CDC provides culturally competent capacity-building assistance to IHS prevention programs, such as the Project Red Talon, ${ }^{9}$ which works to achieve a more coordinated national and Northwest tribal response to HIV. Community-based interventions, such as CDC's Let's Stop HIV Together** media campaign might also help to reduce HIV-related stigma (7).

Because of historical factors affecting AI/AN populations, AI/AN patients receiving HIV care face unique circumstances that might interfere with their ability to achieve sustained viral suppression, including a high prevalence of poverty, depression, stigma, and substance use. It is important that HIV providers and clinics screen for these issues and offer referrals to mental health services and HIV peer group support as appropriate. Many community-based and tribal organizations are positioned to help AI/AN populations access culturally appropriate HIV and ancillary services to improve their health outcomes and reduce HIV-related health disparities.

\footnotetext{
Ittps://npin.cdc.gov/featured-partner/project-red-talon.

** https://www.cdc.gov/actagainstaids/campaigns/lsht/.
} 


\section{Acknowledgments}

Participating Medical Monitoring Project respondents, facilities, providers, advisory boards, and project areas.

Corresponding author: Amy R. Baugher, yda1@cdc.gov, 404-639-1956.

${ }^{1}$ Division of HIV/AIDS Prevention, National Center for HIV/AIDS, Viral Hepatitis, STD, and TB Prevention, CDC; ${ }^{2}$ Epidemic Intelligence Service, CDC; ${ }^{3}$ ICF International, Rockville, Maryland.

All authors have completed and submitted the ICMJE form for disclosure of potential conflicts of interest. No potential conflicts of interest were disclosed.

\section{References}

1. CDC. Diagnoses of HIV infection in the United States and dependent areas, 2016. HIV surveillance report: vol. 28. Atlanta, GA: US Department of Health and Human Services, CDC; 2017. https://www.cdc.gov/hiv/pdf/ library/reports/surveillance/cdc-hiv-surveillance-report-2016-vol-28.pdf

2. CDC. Improving HIV surveillance among American Indians and Alaska Natives in the United States. Atlanta, GA: US Department of Health and Human Services, CDC; 2013. https://www.cdc.gov/hiv/pdf/policies_ strategy_nhas_native_americans.pdf

3. Bertolli J, Lee LM, Sullivan PS; AI/AN Race/Ethnicity Data Validation Workgroup. Racial misidentification of American Indians/Alaska Natives in the HIV/AIDS reporting systems of five states and one urban health jurisdiction, U.S., 1984-2002. Public Health Rep 2007;122:382-92. https://doi.org/10.1177/003335490712200312
4. CDC. Understanding the HIV care continuum. Atlanta, GA: US Department of Health and Human Services, CDC; 2017. https://www. cdc.gov/hiv/pdf/library/factsheets/cdc-hiv-care-continuum.pdf

5. CDC. Behavioral and clinical characteristics of persons receiving medical care for HIV infection-Medical Monitoring Project, United States, 2013 cycle (June 2013-May 2014). HIV surveillance special report: no. 16. Atlanta, GA: US Department of Health and Human Services, CDC; 2016. https://www.cdc.gov/hiv/pdf/library/reports/surveillance/ cdc-hiv-hssr-mmp-2013.pdf

6. Do AN, Rosenberg ES, Sullivan PS, et al. Excess burden of depression among HIV-infected persons receiving medical care in the United States: data from the medical monitoring project and the behavioral risk factor surveillance system. PLoS One 2014;9:e92842. https://doi.org/10.1371/ journal.pone.0092842

7. Baugher AR, Beer L, Fagan JL, et al.; Medical Monitoring Project. Prevalence of internalized HIV-related stigma among HIV-infected adults in care, United States, 2011-2013. AIDS Behav 2017;21:2600-8. https://doi.org/10.1007/s10461-017-1712-y

8. Pfeiffer PN, Heisler M, Piette JD, Rogers MA, Valenstein M. Efficacy of peer support interventions for depression: a meta-analysis. Gen Hosp Psychiatry 2011;33:29-36. https://doi.org/10.1016/j.genhosppsych.2010.10.002

9. Bradley H, Mattson CL, Beer L, Huang P, Shouse RL; Medical Monitoring Project. Increased antiretroviral therapy prescription and HIV viral suppression among persons receiving clinical care for HIV infection. AIDS 2016;30:2117-24. https://doi.org/10.1097/QAD.0000000000001164

10. Ramisetty-Mikler S, Ebama MS. Alcohol/drug exposure, HIV-related sexual risk among urban American Indian and Alaska Native Youth: evidence from a national survey. J Sch Health 2011;81:671-9. https:// doi.org/10.1111/j.1746-1561.2011.00643.x 